\title{
Employee referrals: a study of 'close ties' and career benefits in China
}

\author{
Wen Wang ${ }^{\text {a }}$, Roger Seifert ${ }^{\mathrm{b}}$, \\ a University of Wolverhampton Business School, Wolverhampton, WV1 1AD, West \\ Midlands, UK \\ b University of Wolverhampton Business School, Wolverhampton, WV1 1AD, West \\ Midlands, UK
}

\begin{abstract}
This study examines the relationship between employee referrals and employees' job tenure through the lens of social capital theory. It does so by considering the tie strength (closeness of guanxi) between referrers and referred employees in the Chinese context. In particular, we examine the mediating effect of career benefits. We theorize that close guanxi has a significant and positive impact on the job tenure of referred employees, and that career benefits (such as having a managerial role) mediate the close guanxi effect on job tenure. This highlights the critical need to recognize the tie strength as between referrers and referred employees. The support for our hypotheses comes from the use of personnel records of 4,030 employees over 13 years in one large privately-owned manufacturer in China. Our study has theoretical and practical implications for the relational approach to tackle voluntary turnover in the workplace.
\end{abstract}

Key words: social tie strength, recruitment, staff retention, guanxi, China

\footnotetext{
${ }^{1}$ Corresponding author. University of Wolverhampton Business School, WV1 1AD, Wolverhampton, UK. E-mail: WenWang@wlv.ac.uk
} 


\section{Introduction}

Family and friendship (kith and kin) networks have been used for advancement across the ages and continents. In the modern era, first after 1945 with the spread of labour markets, and later in the 1980s with financialization and free movement of labour (post-Soviet globalisation) such varied systems of privilege were increasingly questioned. Those in favour of the free market neoliberal school of management wanted more worker mobility and flexibility based on talent, a skilled division of labour, and scarcity. Those from the more traditional state-managed economies wanted more merit and less prejudice. The actual operational use, therefore, of this form of social capital in the sphere of recruitment and retention really matters and is a central part of the labour mobility debate in China (Bian \& Huang, 2015b; Chen \&Chen, 2009; Han \& Han, 2009).

Guanxi, personal connections, refers to the state of being related through particular ties to others. Guanxi itself is both a workplace subset of the practical use of social capital, and a uniquely Chinese cultural form that goes beyond the usual familial network (Han \& Han, 2009; Lin, 2001). Although the practice of guanxi may be ancient, its importance in the workplace is still much discussed (for a review see Chen, Chen, \& Huang, 2013). Guanxi has for a long time been widely used to attain an urban job in mainland China (Bian, 1997; Bian \& Huang, 2015a; Zhao, 2013). Our key concern is its impact on the increasingly burdensome problem of voluntary staff turnover (Hom \& Xiao, 2011; Liu \& Peng, 2007). Job switching has now reached a damagingly high level with an average staff voluntary turnover rate of 17\% nation-wide since 2011 (China Daily, 2015). The issues examined here, therefore, focus on the enduring nature of social 'ties', guanxi, as a rational labour market device for better recruitment through employee referral, when compared with formal recruitment methods (e.g. newspapers, advertisements, agents).

The overarching nature of the concept of social capital was drawn from David Hume's (1777) concerns with the beneficial nature of co-operation based on socially-constructed mutual trust and specifically aimed at avoiding the mutual destruction outlined by Thomas Hobbes (1651) in his views of the 'state of nature as a state of war' (Putnam, 2001). This in turn is rooted in interlocking group dynamics governed by social norms. Social capital is here used as the general theoretical basis for studies of 'close ties' before, during, and after entry to the labour market and employment. However, both weak tie theory (Granovetter, 1973) and social resource theory (Lin, 1990) state strong ties (defined as emotionally intense and frequent, such as those with friends and co-workers) tend to provide redundant information, and to possess fewer useful resources for career attainment, instead weak ties are more likely to offer unique information about job openings and to reach superior social resources for career success. Therefore, referred employees attain career benefits (such as higher wages) through a network of weak ties, and also stay in post longer. To date, empirical research has provided mixed findings in this area with some studies confirming the existence of a higher starting wage among referred employees through the oldboys (girls) network (Brown, Setren, \&Topa, 2012; Fernández, Castilla \& Moore, 2000; Simon \& Warner, 1992), but other studies did not find a wage premium and there may even be an earnings’ 
penalty among referred employees (Burks, Cowgill, Hoffman, \&Houseman, 2005; Pellizzari, 2010). Nevertheless, employee referrals uniformly exhibited a longer tenure in all the above studies.

We propose that the effect of social capital pertinent to trust, loyalty, and commitment, is more likely to be found in strong rather than weak ties, and that the resignation behaviour of referred employees has been overlooked in this. Information flows more efficiently the stronger the ties between job applicants and referrers (Han \& Han, 2009). Even Granovetter (1974) stated that the merit of strong ties should not be underestimated. Social support allows new recruits to adjust better and settle in faster (Fang, Duffy, \& Shaw, 2011). Referrers are more likely to provide advice on career development and support to those closely connected than those distantly related. In addition to a higher starting salary and promotion, there are other subjective career benefits (person-environment fit and career satisfaction) (Allen, Eby, Poteet, Lentz, \&Lima, 2004; Seibert, Kraimer,\& Liden, 2001). We revisit the tie strength framework and explore the mechanism by which close guanxi may lead to longer tenure of the referred employees.

This approach contributes in three ways. First, we distinguish the strength of ties between referrers and referred employees in the guanxi framework, and its direct influence through guanxi norms on the length of job tenure. Second, we explicitly explore the mediating effect of career benefits (career advancement) of stronger ties, close guanxi, on prolonged job tenure in order to further explore the influence of social capital, as opposed to the benefits of weak ties (Granovetter, 1973, 1974). Thirdly, the present study applied survival analysis to 4,030 employees' personnel records over 13 years. This unusual access to the data enabled us to map personal connections and employee behaviours at the workplace, which is particularly valuable in China where the difficulty of accessing data is well known (Cooke, 2009).

The next section explores the closeness of guanxi, career benefits, and job turnover among referred employees. It then develops hypotheses to examine the direct (guanxi norms) and indirect (career benefits) influence of close guanxi on employee turnover. A brief description of the data source follows before the paper concludes with a discussion of the results and their theoretical and practical implications.

\section{Guanxi and employee referrals}

Guanxi has been widely considered as a key Chinese socio-cultural concept that provides insight into Chinese society. Researchers have examined the influence of guanxi at the micro (individual and interpersonal) and macro (the organizational, industry, societal) levels (Chen et al., 2013). At individual level, guanxi refers to the state of being related through particulate ties between two or more individuals (Chen \&Chen, 2009; Lin, 2001). Based on the level of obligations and reciprocity, guanxi has been differentiated into familial and kinship, friends (at school, work or social life), acquaintances, and strangers (Han \& Han, 2009; Tsui \& Farh, 1997). Friendship can be seen as important as family to the individuals concerned (Lin, 2001). 
Guanxi has instrumental value for the parties at the workplace (Hwang, 1987), and has traditionally been part of the labour market system for those wishing to attain urban jobs under the planned economy (Bian, 1997). It was predicted to decline with institutional changes in the 1990s (Guthrie, 1998), but an ever-increasing use of guanxi for job searches and recruitment in the transitional economy has been well documented in recent years (Bian \& Huang, 2015a; Zhao, 2013). This may reflect a society with tendencies towards familial collectivism alongside general low trust of others (Chua, Morris, \&Ingram, 2009; Yamagishi \& Yamagishi, 1998). Guanxi is extensively used to cope with labour market uncertainty by both job applicants and employers. Empirical studies show that HR managers believe that network-based recruitment is more timeefficient and more likely to attract highly competent applicants (Han \& Han, 2009).

\subsection{The direct effect of close guanxi and job tenure}

Closeness of guanxi overlays tie strength (Granovetter, 1974). Family is the core component of strong ties, while acquaintances are designated as weak ties. However, the most common base of guanxi is institutional, such as sharing the same birthplace, graduating from the same school/college, and working in the same organization (Chen \& Chen, 2009; Chen et al., 2013; Hwang, 1987; Tsui \& Farh, 1997). Close guanxi can be naturally extended to non-family connections when close friendships are seen as family-like. Close guanxi are characterized by higher levels of sentiment and obligation compared with distant guanxi. In practice, guanxi strength has been predominately measured by labelling, such as family, friends, acquaintance or stranger. Others have attempted to incorporate the frequency of interactions in the measurement as well (Hom and Xiao, 2011), but it is generally agreed that family and friends are stronger than acquaintances and this is used as close guanxi in our discussion.

Distant guanxi (weak ties) may enable individuals to go beyond their usual social circles, and serve as bridges across social boundaries, with the resulting social mobility leading to better jobs (Granovetter, 1982). However, close guanxi (stronger ties) provide a stronger motivation to be of assistance and are typically more readily available, therefore the bonding of close guanxi leads to a stronger sense of obligation and reciprocation towards the action of reference, compared with unreciprocated nature of distant guanxi or no guanxi. Fidelity to close guanxi transfers to the embedded organization and so those referred in this way may be more reluctant to quit. This makes it a key component of reducing voluntary turnover.

In the Chinese context, the closeness of guanxi dictates the degree of compliance with guanxi norms, the obligation and reciprocity to the employment referral in this context. The offer of a job to an applicant who has been recommended (by phone or face to face) by a current employee is perceived as showing trust in the referrer by the employer. The referrer is given mianzi (dignity and prestige), which is defined as recognition by others, the employer in this case, of an 
individual's wisdom or social standing (Hwang, 1987; Lockett, 1988). This will enhance the social position of the referrer, who is viewed as a capable and respectable person. On the one hand it is paramount for the appointee to make reciprocal gestures and to express commitment to the guanxi. The obvious way for the appointee to do so is to be a good employee over a long period, as this will vindicate the referrer's wisdom in selecting suitable candidates. This also increases the referrer's social standing or reputation (mianzi) in the community (network). On the other hand the referrer is more likely to apply pressure on the closely connected appointee than a distantly connected one to perform well and/or have longer tenure in order to maintain their own mianzi. Mutual obligation towards the guanxi norms is more likely to work between close guanxi than distant ones (Bian, 1997; Lin, 2001). Therefore, employees recommended by a close guanxi are more likely to stay longer, this leads to our hypotheses 1.

Hypothesis 1a: Distant guanxi is positively associated with job tenure.

Hypothesis 1b: Close guanxi has a stronger association with job tenure than distant guanxi

\subsection{The indirect effect of close guanxi and job tenure}

Close guanxi, stronger tie, is more likely to lead to career benefits for the following four reasons: first, there is stronger motivation to assist new recruits from the referrers. Trust and obligation ensure a higher quality of information transfer between the job referrer and the applicant (Han \& Han, 2009), and a better estimation of skill sets which tends to produce a better job-person match (Antoninis, 2006). Second, a close guanxi may lead to better adjustment due to the referrers' voluntary "after hire” care, such as coaching, mentoring and even monitoring (Fang et al., 2011). A meta-analysis review shows that mentoring is generally positively associated with career benefits of the protégé (Allen et al., 2004). Meanwhile, the appointee may put extra effort into living up to the expectations of the referrers driven by the incentive to maintain the close guanxi. Thirdly, referred employees benefit from better access to information and resources, shared by the referrers. Closeness of guanxi facilitates information diffusion and access to resources, inter alia, training, promotion, pension, and other benefits (Pallotti \& Lomi, 2011; Zhang, Liu, Loi, Lau, \& Ngo, 2010), which advance the referred employees with regard to career attainment. Friendship with the referrer can help the newly recruited member of staff to settle down. Difficulties in integrating with workplace culture are reported to be one of the main reasons for newly recruited graduates to quit their posts (Xinhua News, 2016). Fourthly, referred employees may be advantaged by favouritism: social networks provide incentives to refer less well qualified workers (Beaman \& Magruder, 2012). For example, studies show that parents who are in strong occupational positions positively affect their children's access to high prestige occupations (Lin \& Dumin, 1986; Kramarz \& Skanz, 2014), and that job attainment through guanxi with key helper (managerial role) or familial ties generated a greater return on starting salary (Bian \& Huang, 2015b; Cheung \& Gui, 2006; Zhao, 2013). 
Holding a managerial role can be a strong indicator of the career benefits derived from close guanxi at the workplace. The privileges of close guanxi are characterized as a form of favourexchange among the in-group members, which is the dominant principle of interaction among friends and the necessary ingredient to maintain friendship in Chinese guanxi development (Tsui \& Farh, 1997). Referrers are more likely to engage in favour exchanges with those in a strong rather than a weak tie relationship (Chen \& Chen, 2009), and such favour exchange may advantage the referred employees in terms of career progression and work-related benefits. Promotion in Chinese firms, even Chinese Multinational Enterprises, is to an extent subject to guanxi with senior managers (Shen \& Edwards, 2004; Wei, Liu, Chen \&Wu, 2010). Having a managerial role is related to higher nominal earnings and other (or hidden) benefits. For example, a positive correlation was found between being a manager and the level of hidden incomes in China (Gao, Ying, \& Luo, 2015). Thus salary enhancement and pension rights, typical benefits of close ties in the Western context, may be less accurate in reflecting the career benefits of an employee in China. The former is underestimated by the long existence of hidden-income in the form of benefits, such as houses and cars, as a means to avoid tax (Gao et al., 2005; Wang \& Woo, 2011). The latter is less valuable to workers in China for two reasons: it is very difficult to transfer pensions among provinces, autonomous regions, municipalities and special administrative regions; and due to severe problems with widespread reported cases of the socalled "empty account" in pension funds (known as 'black holes' in the UK) due to weak state regulation of pension schemes (Cai \&Cheng, 2014; James, 2002; Li, 2012).

Becoming a manager indicates the extent to which the member of staff is likely to be promoted and therefore benefit from higher wages and a stronger career path (Lazear \&Rosen, 1981). Extant research has extensively shown that managers are associated with higher organizational commitment and job satisfaction and, therefore, have demonstrated a higher intention to stay (Griffeth, Hom, \& Gaertner, 2000; Schreurs, Guenter, Schumache, van Emmerik, \&Notelaers, 2013). We, therefore, propose that the impact of close guanxi on job tenure is partially mediated by career benefits associated with holding a managerial position. That is to say that the association between close guanxi and job tenure would weaken once the promotion to a managerial role is included in our module. This leads to our hypotheses 2 .

Hypothesis 2a: Close guanxi is positively related to having a managerial role Hypothesis $2 \mathrm{~b}$ : Having a managerial role partially mediates close guanxi and job tenure

\section{Methods}

Because the practices of guanxi are both personal and confidential, the usable dataset needs to satisfy two conditions: the identification of the closeness of guanxi, and information on employee benefits. We gained access to one large domestic privately-owned enterprise with more than 1,000 employees on its payroll. This is a valuable source since survey data collected among Chinese employees tends to be of little use because of the low trust in China of this type of data collection method (Chua et al., 2009). For example, Hom and Xiao (2011) discovered that 
employee self-rated closeness of guanxi in the organization has a significant association with reported intention to stay at the time, but has no association with voluntary turnover behaviour later on.

The company manufactures textiles and is located in the South of Jiangsu province of China. Production includes weaving, fabric dyeing, and making denim. More than $70 \%$ of the output is exported to North America, the EU, Africa, and other Asian countries. After excluding the three founders of the company to avoid bias in job tenure analysis and those made compulsorily redundant (firing) and retiring, there are 4,030 personnel records between 1994 and 2007. These records include current workers who were hired before 1999, and all workers hired afterwards due to the computerisation of the system in 1999. The data may underestimate the level of staff turnover, but this should have only limited effect on the research questions. Of these records, 2,352 (58\%) were voluntary terminations, and the rest were employees who remained with the organization at the end point of the study period.

The personnel records are not panel data, for example, for job title, we only have the workers' current position or position before they quit. Among these 4,030 employees, $44 \%$ are male and $46 \%$ are married, and the average age is 25 . Qualification is recorded as any formal schooling, such as primary school (5/6 years); lower middle school (8/9 years); senior middle school (11/12 years); vocational (or continued professional development certificate) (14/15 years), tertiary education (first degree 15/16 years, master $17 / 18$ years and $\mathrm{PhD}, 20 / 21$ years) ${ }^{2}$. About $64 \%$ of the sample has less than 9 years schooling (completed lower middle school), $17 \%$ have senior middle schooling (10-12 years subject to completion), $10 \%$ have vocational qualifications, and the remaining $9 \%$ have a tertiary education.

Over $70 \%$ of the sample are employees on the production line with the rest working in nonmanufacturing jobs, such as production control (14\%). Other functional offices include: general administration, HR, accounting, marketing, IT support and media, and make up 3\% of the sample. Sales (3\%), and logistics (5\%), such as drivers, security guards and catering staff at the onsite refectory make up the remainder. Hukou is the household registration system in China. It is an internal passport that gives people and their children subsidised schooling and healthcare, but only in the place where they are registered (Liu, 2005; Wang and Moffatt, 2008). Seventeen percent of the sample is from Jiangsu province, coded as local Hukou, while the rest are migrant workers. Pension rights are measured by whether or not the employee was recorded as having a pension. There are 565 employees in this group representing about $13 \%$ of the total sample.

\subsection{Measurements}

\footnotetext{
${ }^{2}$ For a detailed explanation how children progress in China see Beale., A. (2008) A Chinese Education, Open Learn, The Open University
} 
Exact information is available on each individual's start and end date of employment at this company, along with their job titles, qualification, work department, hukou status, and methods of recruitment.

Independent variables

Closeness of guanxi

It is recorded within the data the method by which each employee was recruited. This includes, inter alia, formal methods such as job fairs, recruitment agents, internet recruitment, as well as employee referrals, such as with an introduction by an employee of the company at the time who is an acquaintance, or recommendation by a family member, relatives, school friends, or former colleagues of the appointee. Such connections were revealed by both employee referrers and the referred applicants, indicating their own evaluation of closeness of guanxi. Employees recruited by formal methods only accounted for $16 \%$ of the total records. This reflects the prevalent use of network-based recruitment in China (Han \& Han, 2009). Employees recruited by acquaintances accounted for $78 \%$ of the sample, with the rest (272 employees) being recruited through a familial or institutional guanxi. Due to the cultural-centric nature of the Chinese guanxi network, and the label of relations which indicate the self-assessed closeness of guanxi by the referred employees (Chen \& Chen, 2009; Chen et al., 2013), we then coded closeness of guanxi as $1=$ formally recruited; $2=$ distant guanxi (recruited by an acquaintance); $3=$ close guanxi (recommended by family members or a named connection).

Career benefits

We use the current job title or the title before quitting to measure objective career benefits. Having a managerial role includes being a team leader (Banzhang), line manager, office head and deputy head (Zhuren and Fuzhuren) and departmental managers and deputy manager (such as Zongjinli and Fu Zongjingli). There are 176 employees in the sample with a job title indicating some form of management position, and this accounted for over $10 \%$ of the workforce, but only $4 \%$ of the studied sample.

\section{Dependent variables}

Staff turnover: the start and end date of employment was used to track voluntary turnover. The unit of job tenure is measured in months. The employment spell ranges from half a month (newly recruited) to 13 years, although the median of tenure is 12 months; the average tenure is 22 months, and only $10 \%$ of the sample had a job tenure longer than 4 years. This reflects high staff turnover more generally in the domestic privately-owned enterprise in China, which is reported being over 30\% in the last two decades (China Daily, 2015).

Control variables 
In the analysis, we controlled for age (in years), gender ( $0=$ female, $1=$ male), Hukou status ( 0 =migrants, $1=$ Jiangsu province Hukou), pension rights ( $0=$ no pension plan; $1=$ offered pension), and schooling in years (primary school=5; low middle school=8; senior middle school=11; vocational school=14 and tertiary education=18). In Table 1, formal education is measured in years of schooling, but is used as a categorical variable in the regression (Tables 2 \& 3). Work department is also measured as a categorical variable which includes production line as the base group; production control office or laboratory; other functional offices; sales; logistics department. It was also coded as a dummy variable (production line=0; the rest=1) in the correlation metric (Table 1).

The rationale for controlling these important variables was to enhance the credibility of our results. For example, staff turnover among migrants is significantly higher than turnover among locals (Cooke, 2009) due to constraints imposed by Hukou. Empirical evidence from some Western companies supports the assumption that offering pensions, as deferred compensation, is an effective way of staff retention (Gustman, Mitchell, \& Steinmeier, 1994; Munnell, Aubry, \& Sanzenbacher, 2015). Considering the value of pension in the private sector in China, it may also lead to a longer tenure. Both qualification and work department indicate the capacity for an employee to find a new job, which may result in higher turnover. That is to say, skilled workers and those with general skills, rather than firm-specific skills, such as salesperson, are more likely to find a new job in a strong labour market.

\subsection{Empirical methods}

A condition for mediation to be relevant was that guanxi has to be significantly related to job tenure. Generally, having a managerial role is positively related with job tenure, but closeness of guanxi has a smaller or non-significant relationship when the mediator is included.

We have chosen to use Cox regression (also known as survival analysis) as the statistical method. Unlike parametric methods, Cox regression is a semiparametric technique in which the dependent variable is the amount of time until an "event" occurs (employee voluntarily quits the organization, Hosmer, Lemeshow, \& May, 1999). The dependent variable of "time” can be thought of as a function of how quickly (or slowly) the voluntary turnover occurs (or is right censored). As such, our selection of survival analysis to test the influence of guanxi and career benefit is appropriate for capturing the voluntary resignation behaviour itself, but also the timing of this behaviour. Several researchers have noted the advantages of using survival modelling to analyse personnel data (Carr, Boyar, \& Gregory, 2008; Mossholder, Settoon, \& Henagan, 2005).

The development and use of a Cox's proportional hazards model requires proportional hazards to stay over time (Hosmer et al., 1999), that is to say the effect of a predictor variable, guanxi, on 
the probability to resign is the same at all time points. This assumption is very likely to be violated since the strength of guanxi depends on time, the relationship between employee referrers and appointed employee can become stronger or weaker over time. This can be verified by graphic methods and by including interaction items. The former is based on the plot of Kaplan-Meier estimator of survival function presented separately for each group. If the assumption is satisfied, the plot should present several curves with distance between them that does not change over time. The latter adds an interaction of the predictor and time, if such a variable turns out to be statistically significantly, it indicates that the proportional hazard assumption might be violated.

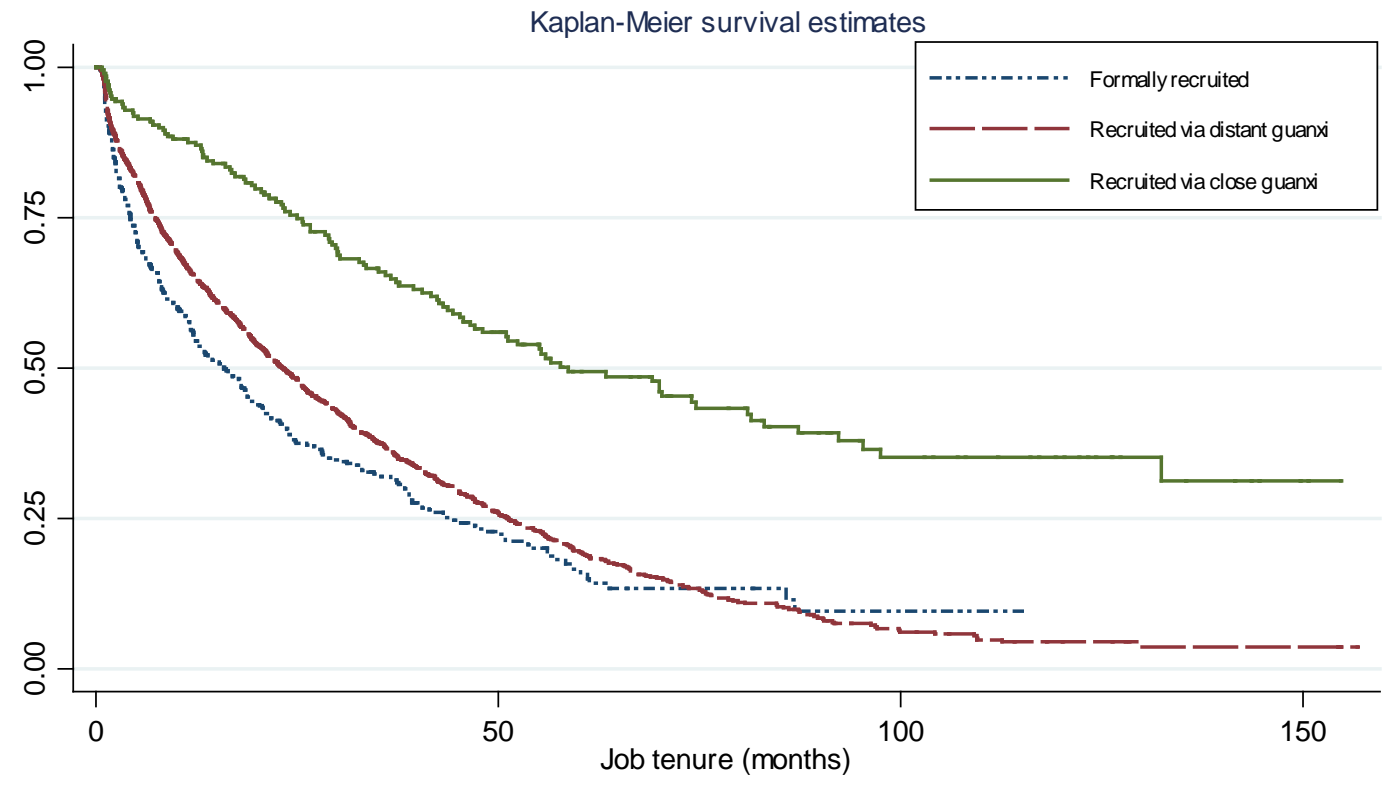

Figure 1 Kaplan-Meier survival analysis

Figure 1 shows a Kaplan-Meier plot of the survival curves for employees recruited through formally (short-dash and dot line), distant guanxi (long dash) and close guanxi (solid line), close guanxi shows high survival rates (retention) over time. An initial advantage of distant guanxi was overtaken by those formally recruited after 5 years. This suggests the effect of distant guanxi on employee resignation diminishes over time. This may be because personal attachments decay rapidly overtime (Burt, 2001), and/or the firm and workers learn about actual worker productivity after the appointment (Dustmann, Glitz, \&Schoenberg, 2015). The interaction variable between distant guanxi and the length of job tenure is also significant, indicating the effect of distant guanxi changes over time. The evolvement of the hazard ratios over time of guanxi can be modelled in a smooth way by adding a time-dependent covariate in a Cox proportional hazards model (Hosmer et al., 1999; Hougaard, 2012). The most straightforward way to do this is by adding interaction terms of the predictor variable and the prognostic variable with a function of time (length of job tenure), a popular choice is $\ln \left(\_t\right)$. 


\section{Results}

Means, standard deviations and correlations between variables are given in Table 1. All of the study variables appear correlated in the direction expected. This is particularly interesting because having a close guanxi is positively correlated with migrants, less schooling, and those who work in the production department. This reflects the fact that low-skilled migrant workers compensate for their disadvantage with beneficial effects gained through close guanxi. In addition, years of schooling is significantly and positively correlated with pension rights and managerial roles. This shows the development of meritocratic practices in the private sector in China. A Variance Inflation Factor (VIF) test shows the value is less than 2 (not exceeding the threshold value VIF $>4$; so multi-collinearity is not a concern for the regression).

Table 1 correlation on main variables

\begin{tabular}{|c|c|c|c|c|c|c|c|c|c|c|c|}
\hline & Variables & Mean (S. ED) & 1 & 2 & 3 & 4 & 5 & 6 & 7 & 8 & 9 \\
\hline 1 & Male worker & $0.44(0.49)$ & 1 & & & & & & & & \\
\hline 2 & Age & $25(7.27)$ & $0.18^{* *}$ & 1 & & & & & & & \\
\hline 3 & Pension rights & $0.13(0.33)$ & $0.07^{* *}$ & $0.11^{* *}$ & 1 & & & & & & \\
\hline 4 & Managerial role & $0.04(0.20)$ & $0.07^{* *}$ & $0.18^{* *}$ & $0.23 * *$ & 1 & & & & & \\
\hline 5 & Local Hukou & $0.17(0.37)$ & $0.03^{*}$ & $0.25 * *$ & $0.25 * *$ & $0.17^{* *}$ & 1 & & & & \\
\hline 6 & Years of schooling & $8(2.55)$ & $0.13^{* *}$ & 0.02 & $0.50 * *$ & $0.21^{* *}$ & $0.37^{* *}$ & 1 & & & \\
\hline 7 & Non-production line jobs & $0.27(0.44)$ & $0.09 * *$ & $0.24 * *$ & $0.21 * *$ & $0.17^{* *}$ & $0.26^{* *}$ & $0.29 * *$ & 1 & & \\
\hline 8 & Closeness of guanxi & $1.9(0.45)$ & -0.01 & $0.08^{* *}$ & $-0.23^{* *}$ & $0.22^{* *}$ & $-0.22^{* *}$ & $-0.56^{* *}$ & $-0.13^{* *}$ & 1 & \\
\hline 9 & Job tenure (months) & $22(23)$ & $0.08^{* *}$ & $0.04 *$ & $0.22^{* *}$ & $0.28^{* *}$ & $0.06^{* *}$ & $-0.04 * *$ & $0.10^{* *}$ & $0.23^{* *}$ & 1 \\
\hline
\end{tabular}

Note:*p<0.05, ${ }^{* *} \mathrm{p}<0.01$

Table 2 reports the results of the Cox regression analyses. We used likelihood ratio tests to examine the effects of entering control and predictor variable blocks into the model, and the Wald statistics to determine whether individual variables were statistically significant. In Step 1, only the control variables were entered into the regression equation. In Step 2, we included the predictors to measure the closeness of guanxi, and then the time-dependent variable by including an interaction item between guanxi and the length of job tenure (in logarithm) within this organization in Step 3. Finally, the mediator variable, having a managerial role, is included in Step 4. The likelihood ratio test indicated that there was a significant improvement in the model fit when including the closeness of guanxi $\left(\Delta \chi^{2}=108.11, \mathrm{DF}=2, \mathrm{P}=0.000\right)$ in Step 2; the interactive items $\left(\Delta \chi^{2}=7.56, \mathrm{DF}=2, \mathrm{P}=0.02\right)$ in Step 3; and managerial role $\left(\Delta \chi^{2}=26.44, \mathrm{DF}=1\right.$, $\mathrm{P}=0.000)$ in Step 4.

Step 3 is then the full model and our interpretation will be based on this specification. Step 4 is used to examine the mediating effect, and will be explained together with Table 3. As shown in Step 3 of Table 2, compared with formally recruited employees, those recruited with guanxi are significantly less likely to resign. However, a distant guanxi is related to a $39 \%$ reduction in the risk of resignation, while a close guanxi is related to $74 \%$ reduction. This provides empirical 
evidence to support Hypothesis 1a and 1b. At the bottom of Table 2 in Step 3, the interaction items show that over time, those recruited by distant guanxi are $12 \%$ more likely to quit compared with those employees recruited by more formal methods, but there is no significant difference between those recruited through close guanxi and the base group. This indicates the diminishing effect of distant guanxi over time.

Table 2: Summary of Cox Proportional Hazard model on length of job tenure

\begin{tabular}{|c|c|c|c|c|}
\hline Predictors & Step 1 & $\begin{array}{c}\text { Step } 2 \\
\text { Coef. (std. err.) }\end{array}$ & $\begin{array}{c}\text { Step } 3 \\
\text { Coef. (std. err.) }\end{array}$ & $\begin{array}{c}\text { Step } 4 \\
\text { Coef. (std. err.) }\end{array}$ \\
\hline \multicolumn{5}{|c|}{ No guanxi (formal methods recruiting) } \\
\hline Distant guanxi & & $0.78^{* * *}(0.08)$ & $0.61^{* * *}(0.08)$ & $0.64 * * *(0.09)$ \\
\hline Close guanxi & & $0.33^{* * *}(0.04)$ & $0.26^{* * *}(0.07)$ & $0.32 * * *(0.09)$ \\
\hline Managerial role & & & & $0.49 * * *(0.07)$ \\
\hline Pension provision & $0.76 * * *(0.06)$ & $0.74 * * *(0.03)$ & $0.76^{* * *}(0.03)$ & $0.78 * * *(0.06)$ \\
\hline Male worker & $0.78 * * *(0.03)$ & $0.78^{* * *}(0.03)$ & $0.79 * * *(0.03)$ & $0.79 * * *(0.03)$ \\
\hline Age (in years) & $1.00(0.00)$ & $1.00(0.00)$ & $1.00(0.00)$ & $1.00(0.00)$ \\
\hline Local Hukou status & $0.82^{* * *}(0.05)$ & $0.84^{* * *}(0.05)$ & $0.84^{* * *}(0.05)$ & $0.84 * *(0.05)$ \\
\hline \multicolumn{5}{|c|}{ Qualification (base group: less than 9 years schooling ) } \\
\hline Senior high schooling & $1.08 *(0.06)$ & $1.11 *(0.07)$ & $1.11 *(0.07)$ & $0.13^{* *}(0.06)$ \\
\hline Vocational qualification & $1.25 * * *(0.09)$ & $1.03(0.12)$ & $1.03(0.12)$ & $1.05(0.12)$ \\
\hline Tertiary education & $2.13 * * *(0.21)$ & $1.72 * * *(0.25)$ & $1.68 * * *(0.25)$ & $1.80^{* * *}(0.25)$ \\
\hline \multicolumn{5}{|c|}{ Work department ( base group: work on production line ) } \\
\hline Control office and laboratory & $0.97(0.06)$ & $1.02(0.06)$ & $1.02(0.06)$ & $1.06(0.06)$ \\
\hline Functional office & $0.54 * * *(0.07)$ & $0.56 * * *(0.09)$ & $0.56^{* * *}(0.09)$ & $0.57^{* * *}(0.13)$ \\
\hline Sale person & $0.69 * *(0.09)$ & $0.70 * *(0.09)$ & $0.69 * * *(0.09)$ & $0.68 * * *(0.09)$ \\
\hline Logistics & $1.18 *(0.12)$ & $1.15(0.11)$ & $1.14(0.11)$ & $1.13(0.09)$ \\
\hline Distant guanxi*ln $\left(\_t\right)$ & & & $1.12 * * *(0.04)$ & $1.09 * *(0.04)$ \\
\hline Close guanxi*ln(_t) & & & $1.11(1.00)$ & $1.11(1.00)$ \\
\hline Number of subjects & 4,030 & 4,030 & 4030 & 4,030 \\
\hline Number of resignations & 2,352 & 2,352 & 2352 & 2,352 \\
\hline Log pseudolikelihood & -17452.36 & -17398.30 & -17394.99 & -17381.23 \\
\hline
\end{tabular}

Note: ${ }^{*}<0.1,{ }^{* *} \mathrm{p}<0.05,{ }^{* * *} \mathrm{p}<0.01$ 
Table 3: summary of Probit regression on managerial role

\begin{tabular}{|c|c|c|}
\hline Managerial role & $\begin{array}{l}\text { Step } 1 \\
\text { Coef. (std. err.) }\end{array}$ & $\begin{array}{l}\text { Step } 2 \\
\text { Coef. (std. err.) }\end{array}$ \\
\hline \multicolumn{3}{|c|}{ No guanxi (base group:formally recruited) } \\
\hline Distant guanxi & & $-0.63 * * *(0.20)$ \\
\hline Close guanxi & & $1.91 * * *(0.18)$ \\
\hline Male worker & $0.18^{* *}(0.08)$ & $0.26^{* *}(0.11)$ \\
\hline Age (in years) & $0.04 * * *(0.00)$ & $0.04 * * *(0.00)$ \\
\hline Local Hukou status & $0.31 * * *(0.09)$ & $0.26 * * *(0.11)$ \\
\hline \multicolumn{3}{|c|}{ Qualification (base group: less than 9 years schooling } \\
\hline \multicolumn{3}{|l|}{ ) } \\
\hline Senior high schooling & $0.50 * * *(0.10)$ & $0.41^{* * *}(0.10)$ \\
\hline Vocational qualification & $0.48^{* * *}(0.12)$ & $0.66 * * *(0.12)$ \\
\hline Tertiary education & $0.79 * * *(0.12)$ & $1.10^{* * *}(0.12)$ \\
\hline \multicolumn{3}{|c|}{$\begin{array}{l}\text { Work department ( base group: work on production } \\
\text { line ) }\end{array}$} \\
\hline Control office and laboratory & $0.57 * * *(0.09)$ & $0.51^{* * *}(0.12)$ \\
\hline Functional office & $0.43^{* * *}(0.16)$ & $0.22(0.19)$ \\
\hline Sale person & $0.14(0.17)$ & $-0.06(0.23)$ \\
\hline Logistics & $-0.19(0.18)$ & $-0.16(0.23)$ \\
\hline Number of subjects & 4,033 & 4,033 \\
\hline Log pseudolikelihood & -587.08 & -353.28 \\
\hline Pseudo R2 & 0.20 & 0.52 \\
\hline
\end{tabular}

Note:* $<<0.1,{ }^{* *} \mathrm{p}<0.05,{ }^{* * *} \mathrm{p}<0.01$

Table 3 presents the probit regression result on determinants with managerial roles. Step 1 shows being male, local, and better educated is significantly linked to having a managerial role. In Step 2 , closeness of guanxi was included. It shows that compared with formally recruited staff, having a close guanxi is significantly and positively correlated with having a managerial role. However, distant guanxi is negatively and significantly correlated with a managerial role even when controlled for qualification, age and hukou status. The model can explain $52 \%$ of employees who had a managerial role and this provides empirical evidence to support the specified condition for mediation in hypothesis 2 a.

Step 4 in Table 2 shows that having a managerial role is significantly and negatively associated with the likelihood to resign, that is to say $51 \%$ less likely in comparison with those who are not managers $(p=0.000)$. The effect of close guanxi on the probability of staying is also reduced by 4 percentage points in comparison to the effect in Step 3. This provides evidence to support hypothesis $2 \mathrm{~b}$. 


\section{Discussion}

2 The present study aimed to advance our knowledge about how staff recruitment through

3 employee referrals, in particular the strength of social ties between referrers and those referred

4 employees, may be a suitable framework to explain longer job tenure among referred employees.

5 In more detail, we explored both the direct and indirect effect of closeness of guanxi in a Chinese

6 company.

8 We found, based on analysis of our unique dataset, that in comparison with formally recruited employees, those referred by an acquaintance or close guanxi, are negatively and significantly related to voluntary resignation over the 13-year recorded period. This fits with earlier findings in virtue of employee referrals (Brown, et al., 2012; Fernández et al., 2000; Mouw, 2003; Simon \& Warner, 1992). Furthermore, employees referred by close guanxi, on average, stayed in work twice as long as those who were formally recruited, and this lower risk of resignation is constant over time. This finding demonstrated that the obligation and reciprocal nature of close guanxi, to maintain the harmony of the in-group community, can act as a complement to the formal contract and regulate employees' behaviour in the firm's internal labour market.

Work has long been recognized as fulfilling the need to belong to a constant community of fellows within the increasingly fragmented nature of modern life (Cartwright \& Holmes, 2006). The closeness of ties with the referrer helps a newcomer to socially embed in the organization and identify the individual to the community of the referrer. This may be particularly valuable among migrant workers. Staff turnover has reached a potentially damaging level in some firms in China, where characterised by a transitional economy powered by millions of migrant workers, who have a record of high occupational mobility. In such conditions of employment social capital can create both stability and feelings of being at 'home'. This phenomenon includes both low skilled migrant workers and graduates, the majority of whom are economic migrants (Wang and Moffatt, 2008). The former have a turnover rate of 40\% (Xinhua News, 2014) and the latter record a 34\% voluntary resignation rate six months after appointed (Xinhua News, 2016). Seeking a higher salary, partly driven by higher inflation, is given as the main reason for resignation in the annual leavers' survey of more than 4,000 employees carried out by a major recruitment agent 51jobs.com in China. However, challenge to integrate into work culture, lack of development opportunity, strained relationship with supervisor or co-workers, and lack of work-life balance are always also among the top five reasons given for quitting (51jobs.come, 2016).

Importantly, this study goes beyond earlier findings by explicitly testing the mediating effect of career benefits (such as having a managerial role) on the relationship between close guanxi and job tenure. We found that employees referred through a close guanxi, familial or a named institutional-based guanxi, compared with formally recruited, are significantly and positively correlated with managerial roles, even when controlling for confounding factors, such as 
1 qualification, Hukou, occupation, and gender. The impact of close guanxi on job tenure, however, 2 is reduced when having managerial role is included in this analysis. This evidence develops the 3 earlier argument that tie strength is important in the employee referral discourse, and referred employees can leverage on close guanxi to be socially embedded on and off the job (Song, 2014; Zhang, 2010), and attain subjective career benefits. They are also more likely to have a smooth career progression as they receive more mentoring, coaching and general support from closely rather than distantly connected referrers.

The career advancement related to close guanxi is also facilitated by the fact that employees in senior positions, such as holding a managerial post, are more likely to be approached by both familial and intuitional-based guanxi for work, who then provide valuable social resources (Lin, 1990). Empirical studies reported higher salaries and better occupational grades derived from strong ties and the status of key helpers (Kramzarz \& Skans, 2014; Lin \& Dumin, 1986; Zhao, 2013). In addition, due to ineffective job matching in the labour market (Bian \& Huang, 2015a), Chinese entrepreneurs often hire family or friends (Wank, 2002; Wellman, Chen \& Weizhen, 2002), and may encourage their managers to do the same. For example, in the data used, we found that senior managers at the company board (4 out of 7) are family members of the three founders. However, this finding is not confined to Chinese national organizations. Large western-owned companies (such as BMW, News International, Michelin) hire family members to senior posts, while at the operational levels, among professional managers, tie strength facilitates career success.

Practical implication

Besides conducting an explicit investigation into network recruiting and employee turnover, this study suggests that recruiting using existing employee guanxi is an effective way to bring about longer tenure at the workplace. This is particularly so when referrers have a close guanxi with the referred employees, be it a family or intuitional-based tie. Loyalty to the guanxi network has a positive spillover effect on the associated organization. This is valuable given the acute staff turnover challenges in Chinese firms.

Even controlling for important potential antecedents to career advancement, employees with a close guanxi are significantly more likely to have managerial roles which mediate the relationship between the observed longer tenure and close guanxi. This may well be attributed to successful socialization facilitated by the closely connected referrers. This aids strong career progress (Fang et al., 2011), typically among a migrant worker dominated workforce. Meanwhile, it raises the concern of potential nepotism at workplace with guanxi (Chen \& Chen, 2009; Warren, Dunfee, \& Li., 2004). Therefore, the labour market challenges faced in the recruitment of new staff through employee networks should be strongly considered. Nevertheless, other beneficial aspects, such as social support, belonging, identity between the closely connected applicant and referrer dyad 
1 disseminative capacity, thereby facilitating knowledge sharing (Michailova \& Hutchings, 2006),

2 which in turn accelerates the creation of new intellectual capital and provides a comparative

3 advantage for organizations (Nahapiet \& Ghoshal, 1998).

Limitations and future directions

It is possible that the specific organizational setting might restrict the external validity of our results. After all, the studied company is a domestic privately-owned enterprise and dominated by low-skilled migrant workers. These types of enterprise have a high turnover rate, over $30 \%$ in the last two decades, whereas state-owned firms have turnover of between 8-12\% in 2014/15 (China Daily, 2015). Furthermore, voluntary staff turnover has spread from the low skilled sector (manufacturing) to the high skilled (graduates) sector, such as high-tech, finance, and ecommerce. In 2014, the former had an average staff turnover rate of $20.2 \%$, whereas the latter is now over 18\% (China Daily, 2015). It will be interesting to examine how institutional-based guanxi, such as university alumnus, influence employee behaviour in the workplace of various types of ownership.

Other research has found that selection and promotion, even in Chinese multinational enterprises, are still subject to guanxi (Shen \& Edwards, 2004; Shen, 2006). With the rapid international expansion of Chinese firms (Ramasamy, Yeung, \& Laforet, 2012), we have little understanding on guanxi and talent retention in Chinese MNEs where equality and diversity is emphasized (Europe) and at locations where Chinese culture dominates (Taiwan, Indonesia, Singapore, Hongkong). Staff turnover has hit the headlines in Hong Kong recently (China Daily, 2014). In a more general sense of the practical meaning of social capital, employee referral is used worldwide, and the development by which friendship bonds are replacing more traditional family bonds requires further research (Pichler \& Wallace, 2006; Spencer \& Pahl, 2006).

\section{Conclusions}

This study has made an initial attempt to advance our knowledge of employee referrals in tackling voluntary turnover by taking into account tie strength (closeness of guanxi) between the referred employee and the referrers in a Chinese company. The findings suggest that recruiting through existing employees' guanxi is an effective way of reducing staff turnover. The survival modelling shows that employees referred by distant guanxi (acquaintance) are moderately and negatively associated with resignation, while those referred by close guanxi (family or a named connection) stay more than twice as long as those recruited by formal methods. Furthermore, our empirical evidence support a partial mediating effect of career benefits (managerial roles) between close guanxi and job tenure. These findings confirmed the importance of tie strength to understand the effectiveness of employee referral and reveal beneficial outcomes for both referred employees and the organization, while also raising the potential challenge of employee referral practices. The 'old school tie' networks are alive and well, and may be a useful counter to 
1 overly restrictive recruitment practices, especially where there remain under-developed labour

2 markets and labour mobility.

3

4 Acknowledgment: We would like to sincerely thank the Editor-in-Chief, Professor Sabina

5 Siebert, and the anonymous reviewer for their valuable and constructive advice, which has

6 significantly improved the paper. The first author would also like to thank her PhD supervisor,

7 Professor Peter Moffatt at the University of East Anglia (UK), for his continuously support and 8 encouragement to develop this paper in the last 10 years.

9 
References

Allen, T. D., Eby, L. T., Poteet, M. L., Lentz, E., \& Lima, L. (2004). Career benefits associated with mentoring for protégés: a meta-analysis. Journal of applied psychology, 89, 127-136.

Antoninis, M. (2006). The wage effects from the use of personal contacts as hiring channels. Journal of Economic Behavior \& Organization, 59, 133-146.

Beaman, L., \& Magruder, J. (2012). Who gets the job referral? Evidence from a social networks experiment. American Economic Review, 102, 3574-3593.

Bian, Y. J. (1997). Bringing Strong Ties Back in: Indirect Ties, Network Bridges, and Job Searches in China. American Sociological Review, 62,366-385.

Bian, Y., \& Huang, X. (2015) a. The guanxi influence on occupational attainment in urban China. Chinese Journal of Sociology, 1, 307-332.

Bian, Y., \& Huang, X. (2015) b. Beyond the Strength of Social Ties Job Search Networks and Entry-Level Wage in Urban China. American Behavioral Scientist, 59(8), 961-976.

Brown, M., Setren, E., \& Topa, G. (2012). Do informal referrals lead to better matches? Evidence from a firm's employee referral system. Evidence from a Firm's Employee Referral System (August 1, 2012). Federal Reserve Bank of New York Staff Report, No.568.

Burks, S. V., Cowgill, B., Hoffman, M., \& Housman, M. (2015). The value of hiring through employee referrals. The Quarterly Journal of Economics, 130, 805-839.

Burt, R. S. (2001). Attachment, decay, and social network. Journal of Organizational Behavior, 22, 619-643.

Cai, Y., \& Cheng, Y. (2014). Pension reform in China: challenges and opportunities. Journal of Economic Surveys, 28, 636-651.

Cartwright, S., \& Holmes, N. (2006). The meaning of work: The challenge of regaining employee engagement and reducing cynicism. Human Resource Management Review, 16(2), 199-208.

Cooke, F. L. (2009). A decade of transformation of HRM in China: A review of literature and suggestions for future studies. Asia Pacific Journal of Human Resources, 47, 6-40.

Carr, J. C., Boyar, S. L., \& Gregory, B. T. (2008). The moderating effect of work-family centrality on work-family conflict, organizational attitudes, and turnover behavior. Journal of Management, 34,244-262

Chen, C. C., Chen, X. P., \& Huang, S. (2013). Chinese Guanxi: An integrative review and new directions for future research. 中国人的关系: 综合文献回顾及未来研究方向. Management and Organization Review,9, 167-207.

Chen, C. C., \& Chen, X. P. (2009). Negative externalities of close guanxi within organizations. Asia Pacific Journal of Management, 26, 37-53.

Cheung, C. K., \& Gui, Y. (2006). Job referral in China: The advantages of strong ties. Human Relations, 59, 847-872. 
China Daily. High Staff Turnover Hits Employers in Hong Kong. (2014). http://www.chinadaily.com.cn/hkedition/2014-10/24/content_18794778.htm/ accessed 27.04.2016

China Daily. Turnover up slightly in workplaces, (2015). http://www.chinadaily.com.cn/china/2015-12/21/content_22758867.htm Accessed 20.04.2016

Chua, R. Y., Morris, M. W., \& Ingram, P. (2009). Guanxi vs networking: Distinctive configurations of affect-and cognition-based trust in the networks of Chinese vs American managers. Journal of International Business Studies, 40, 490-508.

Dustmann. C., Glitz. A., Schoenberg, U. (2015). Referral-Based Job Search Networks. The Review of Economic Studies, 83, 514-546

Fang, R., Duffy, M. K., \& Shaw, J. D. (2011). The organizational socialization process: Review and development of a social capital model. Journal of Management, 37, 127-152.

Fernández, R. M., Castilla, E. J., \& Moore, P. (2000). Social capital at work: Networks and employment at a phone center. American journal of sociology, 105, 1288-1356.

51jobs.com. 2015 Graduates Report, (2016), http://www. reaearch.51jobs.com/insight-376.html/ accessed 19.04.2016

Gao, Q., Ying, Q., \& Luo, D. (2015). Hidden Income and Occupational Background: evidence from Guangzhou. Journal of Contemporary China, 24, 721-741.

Granovetter, M. S. (1973). The strength of weak ties. American journal of sociology,78, 13601380.

Granovetter, M. S., (1974). Getting a Job: A Study of Contacts and Careers. Cambridge, MA: Harvard University Press.

Granovetter, M. S., (1982). The strength of weak ties: A network theory revisited. P.V. Marsden, N. Lin (Eds.), Social Structure and Network Analysis, Sage, Newbury Park,CA, 105-130.

Griffeth, R. W., Hom, P. W., \& Gaertner, S. (2000). A meta-analysis of antecedents and correlates of employee turnover: Update, moderator tests, and research implications for the next millennium. Journal of management, 26(3), 463-488.

Guthrie, D. (1998). The declining significance of guanxi in China's economic transition. The China Quarterly, 154, 254-282.

Gustman, A. L., Mitchell, O. S., \& Steinmeier, T. L. (1994). The role of pensions in the labor market: A survey of the literature. Industrial \& labor relations review, 47, 417-438.

Han, J, \& Han. J. (2009). Network-based recruiting and applicant attraction in China: insights from both organizational and individual perspectives. The International Journal of Human Resource Management, 20, 2228-2249.

Hobbes, T. (1651). The Leviathan, London, Everyman 1937 edition

Hom, P. W., \& Xiao, Z. (2011). Embedding social networks: How guanxi ties reinforce Chinese employees' retention. Organizational Behavior and Human Decision Processes, 116, 188-202. Hosmer, D. W., Lemeshow, S., \& May, S. (1999). Assessment of model adequacy. Applied Survival Analysis: Regression Modelling of Time-to-Event Data, Second Edition, 169-206. Hougaard, P. (2012). Analysis of multivariate survival data. Springer Science \& Business Media, 84-104. 
Hume, D. (1777). A treatise of human nature, Oxford: Oxford University Press. 1978 edition

Hwang, K. K. (1987). Face and favor: The Chinese power game. American journal of Sociology, 92, 944-974.

James, E. (2002). How can China solve its old-age security problem? The interaction between pension, state enterprise and financial market reform. Journal of Pensions Economics \& Finance, 1, 53-75.

Kramarz, F., \& Skans, O. N. (2014). When strong ties are strong: Networks and youth labour market entry. The Review of Economic Studies, 81,1164-1200.

Lazear, E. \& Rosen, S., 1981. Rank-order tournaments as optimum labor contracts. Journal of political Economy, 89, 841-864.

Li, W. (2012). Reflections of China's Pension Model in the Context of an Aging Population . Contemporary Economy \& Management, 4, 12-25.

Lin, N., \& Dumin, M. (1986). Access to occupations through social ties. Social networks, 8, 365385.

Lin, N. (1990). Social resources and social mobility: A structural theory of status attainment. Social mobility and social structure, 247-271.

Lin, N. (2001). Guanxi: A conceptual analysis, In A. So, N. Lin \& D. Poston (Eds.), The Chinese triangle of mainland, Taiwan, and Hong Kong: comparative institutional analysis,Westport, CT: Greenwood Press, 153-166.

Liu, Z. (2005). Institution and inequality: the hukou system in China. Journal of Comparative Economics, 33, 133-157.

Liu, B., \& Peng, L. (2007). Exploration and test of a model of employees' voluntary turnover in China. Frontiers of Business Research in China, 1, 378-384.

Lockett, M. (1988). Culture and the problems of Chinese management. Organizational Studies, 9, 475-496.

Michailova, S., \& Hutchings, K. (2006). National cultural influences on knowledge sharing: A comparison of China and Russia. Journal of Management Studies, 43(3), 383-405.

Mossholder, K. W., Settoon, R. P., \& Henagan, S. C. (2005). A relational perspective on turnover: Examining structural, attitudinal, and behavioral predictors. Academy of Management Journal, 48, 607-618.

Mouw, T. (2003). Social capital and finding a job: Do contacts matter? American sociological review,68, 868-898.

Munnell, A. H., Aubry, J. P., \& Sanzenbacher, G. (2015). Recruiting and Retaining High-Quality State and Local Workers: Do Pensions Matter?. Center for Retirement Research at Boston College Working Paper (2015-1).

Nahapiet, J., \& Ghoshal, S. (1998). Social capital, intellectual capital, and the organizational advantage. Academy of management review, 23(2), 242-266.

Pallotti, F., \& Lomi, A. (2011). Network influence and organizational performance: The effects of tie strength and structural equivalence. European Management Journal, 29, 389-403.

Pellizzari, M. (2010). Do friends and relatives really help in getting a good job?. Industrial \& Labor Relations Review, 63, 494-510. 
Pichler, F., \& Wallace, C. (2007). Patterns of formal and informal social capital in Europe. European sociological review, 23(4), 423-435.

Putnam, R. (2001). Social capital: Measurement and consequences. Canadian Journal of Policy

Research, 2, 41-51.

Ramasamy, B., Yeung, M., \& Laforet, S. (2012). China's outward foreign direct investment:

Location choice and firm ownership. Journal of world business, 47(1), 17-25.

Schreurs, B., Guenter, H., Schumacher, D., Van Emmerik, I. J., \& Notelaers, G. (2013).

Pay-Level Satisfaction and Employee Outcomes: The Moderating Effect of

Seibert, S. E., Kraimer, M. L., \& Liden, R. C. (2001). A social capital theory of career success. Academy of management journal, 44(2), 219-237.

Shen, J., and Edwards, V. (2004). Recruitment and selection in Chinese MNEs. The

International Journal of Human Resource Management, 15, 814-835.

Shen, J. (2006). Factors affecting international staffing in Chinese multinationals (MNEs). The International Journal of Human Resource Management, 17, 295-315.

Simon, C. J., \& Warner, J. T. (1992). Matchmaker, matchmaker: the effect of old boy networks on job match quality, earnings, and tenure. Journal of Labor Economics, 10, 306-330.

Song, Y. (2014). What should economists know about the current Chinese hukou system?. China Economic Review, 29, 200-212.

Spencer, L. \& Pahl, R. (2006). Rethinking Friendship. Hidden Solidarities Today. Princeton USA: Princeton University Press.

Tsui, A. S., \& Farh, J. L. L. (1997). Where Guanxi matters relational demography and Guanxi in the Chinese context. Work and Occupations 24(1), 56-79.

Wei, L. Q., Liu, J., Chen, Y. Y., \& Wu, L. Z. (2010). Political skill, supervisor-subordinate guanxi and career prospects in Chinese firms. Journal of Management Studies 47(3), 437-454.

Wang, W., \& Moffatt, P. G. (2008). Hukou and Graduates' Job Search in China, Asian Economic Journal, 22, 1-23.

Wang, X., \& Woo, W. T. (2011). The Size and Distribution of Hidden Household Income in China. Asian Economic Papers, 10, 1-26.

Wank, D. (2002). Business-state clientelism in China: Decline or evolution. Social connections in China: Institutions, culture, and the changing nature of guanxi, 97-107.

Warren, D. E., Dunfee, T. W., \& Li, N. (2004). Social exchange in China: The double-edged sword of guanxi. Journal of Business Ethics, 55, 353-370.

Wellman, B., Chen, W., \& Dong, W. (2002). Networking guanxi. Social connections in China: Institutions, culture, and the changing nature of guanxi, 221-241.

Xinhua Daily. High Staff Turnover in Labour Intensive Enterprises shows no sign to fall. (2014). Http://www.xh.xhby.net/mp2/html/2014-01/28/content_944741.htm/ accessed 27.06.2016 Xinhua News. More than 30\% Graduates Resign Half a Year after Appointment. 2016. http:wap.jschina.com.cn/js/system/2016/06/13/028915150.shtml/accessed 15.07.2016 Yamagishi, T., \& Yamagishi, M. (1998). Trust and commitment as alternative responses to social 
uncertainty. Network and markets: Pacific Rim Investigations. Oxford University Press, Oxford, 109-123.

Zhao, W. (2013). Social Networks, Job Search, and Job Earnings in a Transitional Economy: An

4 Institutional Embeddedness Argument. Research in the Sociology of Work, 24, 103-34.

5 Zhang, L., Liu, J., Loi, R., Lau, V. P., \& Ngo, H. Y. (2010). Social capital and career outcomes: a 1323-1336.

8 Zhang, H.F. (2010). The Hukou system's constraints on migrant workers' job mobility in Chinese 9 cities. China Economic Review, 21, 51-64. 